\section{HYDROTHERAPY IN NERVOUS FATIGUE *}

CURRAN POPE, M.D.

Medical Superintendent, the Pope Sunatorium; Neurologist to the Loulsville City Hospital

I.OUISVII.IL, IXY.

Fatigue may be defined as an exhaustion of the bodily, nervous or mental powers, or of all combined. In the neural fatigue that we are to consider, it may be stated in broad terms that the person suffers in all the various spheres mentioned. Fatigue in the normal subject is not unpleasant, but a rather delightful preface to restful restoration.

The chemical conditions of fatigue lie in the production of the so-called "fatigue substances," particularly rarbon dioxid and lactic acid. These substances in small quantities increase protoplasmic activity and augment muscular energy. The preponderance of evidence seems to favor the idea that there is a high degree of resistance to fatigue on the part of the brain and spinal cord, as well as the nerve fiber itself.

Fatigue is a general systemic sensation like lumger and thirst; it has its localized sensations, more especially in the eyes and mus'les. Fatigne may become so overbearing as to become painful and destroy the desire of life. Brunton ${ }^{1}$ says that so long as the muscles are connected with the central nervous system complete exliaustion of the muscle is impossible, for before it becomes paralyzed by jts own exertion, the sensation is perceived by the nerve-centers and the nerve stimuli, which proceed to the muscle, are so much diminished that complete paralysis is never produeed. The sensation of fatigue is perceived in the central nervous system but is proluced by peripheral exertion. Fatigue is overcome only by the removal of those products that are the causative factors of the condition, and is therefore a matter of the relative balance between available energy and the resistance against which this energy must work.

We must clearly distinguish between genuine fatigue and that pseudlo fatigue which results from a lack of the habit of industry. As Iee" has remarked, "most of us work too briefly and rest too long." Ofiner" well remarks that subjective symptoms offer an unreliable measure for fatigue, which he was able to substantiate by a study of physical and mental tests. The normally fatigued nervous system of one who has not made great drafts on that wonderful neural reservoir of which William James speaks protects itself by seeking rest and recuperation, and it is now a fairly accepted belief that we often rest because we do not wish to be fatigued.

That the mental attitude has a great deal to do with the question of perception and feeling of fatigue is a well-known fact. The power of music to quicken the steps of the tired soldier, the influence of the emotions in recloubling one's strength, and the driving force of reward displace the feeling of fatigue in many instances. We instinctively feel that fatigue calls for rest; our minds become impressed with this fact and the continued consciousness of the fatigued state serves to intensify the consciousness to a greater or less degree, depending on the suggestibility of the individual.

* Rend in the Section on Pliarmacology and Therapeutles of the American Medical Assoclation, at the Sixty-Fourth Anuual Session, held at Alinneapolis, June, 1913.

1. Brunton, Latuder: On Being Tired; Prnetltioner, London, October, 1910 .

2. Lee, lirederlek s.: The Nature of Fatigue, Pop. Sc. Month. liebruary, 1910.

3. Offncr, Sinx: Dle Gojstige lormildung; Berlin, Reulber and lectehurd, rsiso.

4. Jumes, Whllam : Luergles of Man.

\section{CAUSES OF FA'TIGUE}

Many writers assign our complex civilization as the main cause of neural fatigue, but I would prefer to say that neural fatigue more often results from a lack of adaptability than as the direct eflect of civilization on the central nervous system. It is improper mental work accompanied by irritation and worry rather than mental work per se that breaks one down. Muscular overexertion can undoubtedly bring about neural as well as mental fatigue, owing to the intimnte physiologic connection between the central nervous system and muscular groups; in fact it is not a muscular proposition, but a nemremusenlar one. 'Those who have liad occasion to observe an athlete after strenuous exertion, a Marathon, or a six-clay bicycle race, have noted in this strong healthy person physical and mental symptoms similar to those seen in the neuroses and psychoses. It may be interesting here to note that muscular fatigue is much more quickly reeuperated from than that fatigue which results from prolonged mental strain and worry. When one's labor is pleasing and performed without internal mental friction, the work may be kept up for many months and years without nervous tire, whereas half the snme amount of labor that is disagreeable will be prone to produce nervous breakdown and imperfect work. Labor unsuited to the inclividual is more apt to provoke fatigue than that for which he is specially fitted. If to these conditions of occupation be added insufficient hours of rest, worry, anxiety and the lack of home peace, we may expect nervous latigue. While I believe that the sexual sphere may be productive of many cases of nervons fatigue, still I do not believe that it occupies the somewhat exaggerated position that certain writers scem to give it.

\section{CLASSIFICATION}

I would classify nervous fatigue as follows:

1. Fatigue resulting from inherent nervous weakness; hereditary factor.

2. Fatigue resulting from retained metabolic wastes; non-oxidative factor.

3. Fatigue resulting from toxins; non-eliminative factor; (a) endogenous; (b) exogenous.

4. Fatigue resulting from circulatory defects.

5. Tatigue resulting from organic diseases.

1. Fatigue resulting from inherent nervous weakness. Persons in this class are doomed by hereditary entailment of an unstable nervous system to a life of neural fatigue. They are persons who seem to "short-circuit" their nerve force and are thus "usually run down"; who live an existence on a narrow margin and are constantly making overdrafts on their limited capital.

2. Fatigue resulting from retained metabolic wastes. In this class we find a large number of persons whose metabolic processes, eliminative organs and tissues seem to be inadequate to the demands of caring for the removal of the normal or pathologic wear and tear of the body. A failure to oxidize these waste products is probably largely due to a disturbance of the so-called "internal secretions"; the serretions from the varions ductless glands stimulate the removal of waste and fuvor cell reconstruction. An active circulation for the removal of waste products is a sine qua non, and the influence of hydrotherapy in developing a flexible circulation enables us to bring about brilliant results in these cases,

3. Fatigue from toxins, endogenous and exogenous. A great many, if not the majority of toxins, especially the putrefactive varieties, are produced chiefly in the intestinal canal, and a moderate sterility of this system 
is undoubtedly of great advantage in nervous fatigue. 'The presence of indol, skatol, phenol, ammonia and wher toxic products, to say nothing of the toxins arising from the various bacteria themselves, must be promptly removed. 'That weariness may be produced by the direct action of these chemical substances on the brain itsell and on the motor nerves and muscles is now accepted by many authorities. It is in this way that neural fatigne is often brought about. Bernheim believes that the loxin or toxins circulating in the blood have a specinl affinity for certain tracts in the nervous system and that this is lrequently revealed by exaggeration of tendon reftexes, and further, that the toxic factor often underlies a case that is supposed to be due to some emotional shock, plyssiologic strain or passing infection. He says that surgestion may aid the functional elements, but is powerless against the underlying dyscrasia of the nerrous system.

4. Futigue resulting from circulatory defects. A failure of rirculatory activity is frequently an added (ause of fatigue, supplementing the effects of imperfect metabolic functioning and the formation and retention of toxins of all kinds. 'This may produce a state of hypertension or a great variation of blood-pressure, which is sometimes abnormally low, sometimes alonormally high.

5. Fatigue resulting from organic disease. Neural fatigue resulting from organic defects will, in a given case, depend on those pathologic changes that constitute the disease. Among the most common of all the underlying organic diseases that produce general nervous fatigue must be mentioned arteriosclerosis," in which the sclerotic or fibrotic changes shut off the quantity of blood to the part, depriving it of the power to nutritionally care for itsclf. That many other organic discases produce fatigue and exhaustion is well known, but the loregoing paradigm will serve for the purpose of calling ittention to the necessity of carefully eliminating this lastor in the diagnosis of fatigue conditions.

\section{DIFFERENT'LATION}

It is not possible to separate nerve fatigue according to its causation, save in lare instances. It is well to bear in mind that nervous fatigue is an exceedingly complex condition and that the foregoing causes frequently combine, though one of these conditions may be so predominant as to make it the principal or real cansative factor in the case.

\section{SYMPTOMS}

Pathologic nervous fatigue is induced by minimal exertion, or an exertion that would fail to procluce exhaustion in a normal person. Fatigue, lassitude and exhaustion when established are present even without exertion, and the fatigue is increased by physical as well as mental activity. Fatigue is nearly always associated with a more or less marked emotional condition. Fatigue, irritability, emotionalism and generalized mental depression form the characteristic basis of nearly all cases of nervous fatigue. The diagnosis of neural fatigue is often made when the symptoms are really due to an under'ying organic disease, like tuberculosis or syphilis. Even neurasthenja is not a correct term to cover all cases. Nervous fatigue is very common; genuine neulasthenia, as compared to the number of cases so labeled, night be designated as rare. A much closer restriction of this designation would be beneficial to both physicinn and patient.

5. Burnheim. I. : Ilev. do mell. Paris, 1900, $x \times 1 x$, No. 4

i. Pope Curran: The Genelel Physlologte und Therapellle setion of Iydrotberapy, Jour. Advanc. Therap., Muy, 1008.

\section{MLTIIODS}

'The methods to be employed in the treatment of ner'sous fatigne naturally fall under two categories:

1. General systemic measures, the aim and object of which is to remove the underlying cansative conditions and to tone, strengthen and reconstruct the nervous system.

2. Iocal measures for the palliation or relief of locali\%ed symptoms.

Each of these can be further sublivided into (1) general systemic measures (a.) in the home and (b) sanatorial; (2) local measures (a) in the home and (b) sanatorial.

It is my belief, perhnps hased on personal experience and not perhaps withont bias, that private hospitals or sanatoriums ofter the hest places for the treatment of these patients.

Hydrotherapy is by far the most important of all the physical measures used in the treatment of nervous fatigue. Long experience has led we to the belief that. were I limited to one method alone for the managenient of this disorder, I would unquestionably choose hydrotherapy. 'l'he hydriatic prescription can be intelligently applied to the patient only when it is based on a thorongh diagnostic knowledge of the practical case in hand. With this as a basis and a thorongh knowledge of the plyysiologic action of loydrotherapy and its associative procedures, we are then in a position to "temper the wind to the shorn lamb." It is my opinion that the nervously fatigued do best in some small institution, thoronghly equipped, owing to the neels of complex apparatus, by means of which the various forms of douche can be administered, and to the further fact that the physician in this line of work aequires a knowledge and experience that enables him to readily meet the problems that arise in every case of this disorder.

Hydrotherapy strikes at the root of the trouble: endeavors to remove the underlying cause by physiologic. action, lessens nerve sensitiveness, invigorates and strengthens nerve processes, and raises the general mental feeling of buoyancy. In cases of nervous fatigue. the treatment must be persisted in for some time, from three to six months or even longer. It has for its object not alone the relief of the fatigue, but also a reconstruction that will resist morbid influenees after the putient returns to his former life. It must be borne in inind that the douche to the spine, under various pressules, is a powerful agent in arousing weakened spinal (enters to activity; it develops wide-spread spinal reflexes, improves the nutrition of the cord and centers. by strong fluxive or hyperemic results, to the starved and irritable centers. Few cases are so simplo that they do not require a combination of methods.

The principles that underlie the trentment of nervous fatigue by hydrotherapy and its procedure, together with the methods that can be employed, follows:

1. A preliminary sweating procedure. This draws the blood to the surface, stimulates glandular activity and prepares the patient for the cold application. Methods: Full dry-pack, full wet-pack, vapor or steam; heat, superheated dry hot air, full bath and incandescent electric-light bath. The last-named is undoubtedly the best.

2. A warm application. 'The warm water cleanses the skin by its mecnanical effect, increases the dilatation of the blood-vessels and prepares the patient for reaction. Methods: warm full bath, rain bath, needle bath, 
douche (fan, spray, jet and Scotch), especially applied to the general body surface, spine and liver.

3. $\Lambda$ cold application. 'This is tonic, reconstructive eliminant and rejuvenating. In the nervously fatigued this should always follow sweating procedures and warm applications. Object: to train patients to stand strong pressures and cold temperatures, which should always be bricf. Methods: sponge, aflusion, dripping sheet, hall' bath and aflusion, shower, rain-bath, needle and douche (fin spray, jet and Scoteli).

4. Reaction. This is the absolute essential and fundamental necessity of all hydrintic methols in the treatment of nervous fatigue. Reactions is that sense of glow, stimulation and fecling of pleasure and comfort, combined with a pinking of the skin, a general tonic state of the circulation on the surface, ete., that follows a moderate application of cold.

5. Brevity. All forms of treatment in nervous fatigue should be brief. They should commence with the shortest possible duration, of the mildest temperatures and lowest pressure, all of which are gradually increased. When the maximum application is reached of temperature and pressure it should still be encompassed under the term "brevity."

6. Frequency. The applications may be rade from three to six times weekly, best in the formoon, from two to three hours after eating and usually followed by rest.

7. Patients do best on a combination of methods; for example, an electric-light bath, followed by warm or lot rain-needle, fan or jet, rapidly resluced to a lower temperature, and this in its turn followed by a cold anal douche for constipation. In my experience, which cover's the range of drug, mechanical and so-called plyysiologic methods, I have never yet found anything to equal the rain, necdle and jet douche.

\section{PLANS OF TREATMENT}

Plans of treatment may be divided into those that may be employed $(a)$ at home and $(b)$ at sunitoriums. I lave already ${ }^{7}$ outlined these as follows:

(a) A plan suitable for the liome or for those whose reaction is poor would be the following: bry.pack for from onelenlf to one hour, followed by a cold spoire with water at a temperature of $70 \mathrm{~F}$. for three minutes, with vigorous friction. As soon as this point is renched dispense with the dry-puck and give the dripping-sheet at $65 \mathrm{~F}$. for three minutes, with grood friction, while the patient stands in a foot. tuh of water as hot as ean be borne. Renction must be secured. This treatment is generally administered in the morning, and when this time is selected give the general wet-pack at $05 \mathrm{~F}$. for one hour at bedtime. When the patient is removed from the pack he is rapidly dried and no renction is sought. The advantage of this method of treatment is to obtain the stimu. lating and tonic influenes of the drippina-sheet in the morning and the sedative and sleep-producing effects of the wetpack at bedtime.

Another good method is to lave the patient sit in a half bath with water at from 102 to $104 \mathrm{~F}$,, while the nttendant gives hin an aflusion at $80 \mathrm{~F}$. At this point the pationt should stand in the tub in water as hot as can be borne, while the aftusion is given to the entire boly, or the water is thrown with force against the body from a large dipper. 'This maly be further modified by first immersing the body in warm water, then giving a salt rub or glow, followed by the afrusion. 'The wurm full bath (104 to $105 \mathrm{~F}$.) for five or seven minutes, followed by the salt rub and finally by the eold shower at from 70 to $65 \mathrm{~F}$., will be found useful. Reaction is essential.

7. lope, Curran: Practical Iydrotberany, Clncinnatl Medieal Bools Come, Cutrint! (b) "In institutions or sanatoriums many women and nearly all men may commence with the following, particularly if the patient is up and going about: Jilectric-light bath or hotair bath until perspiration commences, followed by the circular or horizontal rain-bath at from 100 to $104 \mathrm{~F}$. for ono and one-half to two minutes, reduced to $75 \mathrm{~F}$. for one-fourth minute, with a pressure of 20 pounds. Reduce the tempern. ture 2 degrees duily to $60 \mathrm{~F}$. and increase the pressure 2 pounds daily until 30 is registered. After about $n$ week of this treatment we may add to the foregoing the fan douche at a temperature of $60 \mathrm{l}$. to the entire body for from five to ten seconds. The next move should be the following: Electric-light or hot-air bath until porspiration take place, followed by the horizontal or circular rain-bath at 100 to $104 \mathrm{~F}$. for one minute, reluced to $60 \mathrm{~F}$. for from fifteen to twenty seconds, pressure 30 pounds, to be followed by the jet doushe to the spine and logs at $60 \mathrm{~F}$. for five seconds. An excellent method of treating these cases after renetion has been woll established is to apply the jet douche to the spino at a temperature of $105 \mathrm{l}$. for a half to one minute, followed by the jet to the spine at a temperature of $00 \mathrm{~F}$. for ten seconds, increasing the temperature of the hot water 2 degrees daily until 110 or even $120 \mathrm{~F}$. is renehed, at which point it will usually be found that the patient can tolerate no higher temperature. 'This is especially useful in men who are plyssically strong and who complain of persistent "head feelings" and tender spine. Neurastlenics do not, as a rule, stand the Scotch douche well. Certain prominent symptoms often demand special attention.

\section{MBETING SIMCIAI, SYMPTOAS}

Hydrotherapy offers a fertile field for the meeting of the varions symptoms, objective and subjective, that oceur in nervous fatigue.

Insomnia. The insomnia can best be met by the coldpack or dripping-sheet at bedtime, or the so-called "Neptune's girlle" or trunk compress, consisting of a coarso linen bandage wrung out of water at a temperature of $65 \mathrm{~F}$. and covered by several layers of the same material to exclude the air. It should be worn all night. A most excellent method is the neutral bath, temperature from 94 to $96 \mathrm{~F}$. for from twenty to sixty minutes. Simple measures that sometimes produce sleep are the use of Chapman's icc-bag to the spine, or a hot and cold spinal sponge. In addition, we may give from 6 to 12 ounces of warm milk on retiring, either plain or predigested. A short foot-bath should be given.

Headaches and head pressure. For headaches and heat pressure the fomentation applied for five or ten minutes twice, and followed by a cold compress, is very effective. If the headaclie is congestive, the hot footbath should be used, followed by the ice-bag to the nape of the neck and the cold compress to the forehear. Sitz-baths at $90 \mathrm{~F}$., reduced to $65 \mathrm{~F}$., or cold foot-baths, will often give relief. If the headache is persistent, indefinable and annoying, it can sometimes be permanently relieved by means of the Scotch or alternate douche to the spine and legs.

"Spinal irvitation," so-called, or the "neurasthenic spine," is best met by genernl douche treatment to the spine. When this is not effective, the Scoteh douche at from 120 to $125 \mathrm{~F}$. for thirty seconds should be used, followed by a temperature of from 50 to $60 \mathrm{~F}$. for from five to ten seconds, with four alternations. Sometimes the hot and cold spinal spronge nt bedtime is successful.

For eye pains and muscae volitantes the fomentation to the eyes and forehead should be employed, followed by the cold compress for hall an hour, repeated, if necessary, several times daily.

For ovarian irritation and vaginal discharges, hot vaginal irrigation should be used daily or twice daily, 
and hot trunk pack applied sufficiently low down to include the pelvis and hips; that is to say, to the midille of the thighs.

sexual irritations can often be promptly relieved by the hot sitz-bath from 110 to $115 \mathrm{~F}$. for f'rom five to ten minutes, followed by the cold jet douche to hips and lower spine for fifteen seconds.

Menstrual delay and pain are best met by the hot -it\%-bath from 110 to $115 \mathrm{~F}$. for from ten to fifteen minutes, followed by cold affusion over the hips. The warm (not hot) vaginal douche favors the commencement of the period.

For anorexia, a glass of ice-water should be given one hour and the ice-bag applied for half an hour before meals. It is astonishing sonetimes what results will follow this simple treatment.

For dyspepsia nervosa the patient must be placed on weneral treatment, although the trunk pack at a temperature of $65 \mathrm{~F}$. for one hour is sometimes helpful.

Rectal irritation and constipation are greatly benefited ly the use of the perineal and anal douclie as hot as can lie borne, followed by a cold douche of from 60 to $50 \mathrm{~F}$. stronger revulsive effects may be obtained by an altersate hot and cold application.

Colitis and intestinal catarih ale best met by means of the dripping sheet, followed by the sitz-bath from ${ }^{0} 0$ 10 $65 \mathrm{~F}$. for from three to ten minutes, during which time the attendant and patient rub the abdomen and liips thoroughly.

Gastro-cnterocoloplosis is best met by an abdominal supporter and the Scotch or alternating douche to the alilomen, under weak pressure, gradually increased. 'The temperatures may be increased and decreased gradlally.

Backache is often promptly relieved by the jet and s'otch douche or, what is better than all others, the incotel jet douche.

Vertigo is best met by general treatment and the hot and cold jet to the spine.

\section{PREVEN'TION}

Proplyjlaxis and the maintenance of health alter recovery are best secured by a combination of fuctors, of which hydrotherapy is the most important. $\Lambda$ person who has been nervously fatigued should try and adapt himself to reality and to the work he has to do. All hygienic measures and the consistent and persistent use of cold water will maintain a degree of health that is little short of surprising. As I have heretofore remarked, it would be far better for these persons to purchase a good shower bath than many of the ornate pieces of bric-a-brac that frequently adorn parlor's and liorm many dislarmonies.

'The aim of the treatment has been to remove etiologic factors, to stimulate the metubolic processes of the body and change the pathologic state to a normal one. Somelimes health has been obtained even when I could not see that there was a cure from a histologic point of view, but from the physiologic standpoint the recovery lus presented that appearance.

\section{RELATIONS TO DRUG MEDICATION}

It has been my observation that hydrotherapy reinforces and makes much more efficient any drug medication that we may care to administer in conjunction with the liydriatic method. Iron, arsenic and other tonics hecome more effective; smaller doses of bromid and an ahsence of acne is noticouble, especially in epilepsy; hydrargyrum bcomes much more effective and rapid in its action in syphilis; smaller doses of hypnotics are required for insomnia; drug habitues and alcoholics require smaller doses and finally tonic (that is, cold) hydrotherapy requires a much lessened quantity, as well as number of clrugs, in the medisation of gastric dis(1)riters.

\section{MLMAlitis}

Condemmation of unscientific lisdrotherapy cannot be too strongly urged. "How many crimes, O Hydrotherapy, have been committed in thy name!" To this there is no answer. From a consiclerable acquaintance with users of hydrotherapy, I am inclined to belicve that the greatest danger lies in the lack of a real diagnosis, the separation of the sheep from the goats. With a knowledge of its action not alone in nervous fatigue, but also in a whole host of disorder's and diseases, a failure to use it is, in a sense, a medical crime. It is too valuable and important a remedy, too lar-reaching and useful, to be relegated to the charlatan, quack and that abomination of all lydriatists, the "giver of baths." Hydrotherapy belongs to the medical profession; it is a scientific measure, capable of scientific application, and must never again be allowed to drift to ilestruction on the rocks of therapentic nilitism.

\section{CONCLESIONS}

1. Nervous fatigue is a complex state of mind and body, largely toxic.

2. Its origin is due to an inalsility on the part of the individual to adapt himself to heredity, environment and reality.

3. Its symptoms are many and oceur as an entity or in conjunction with many other disorders and diseases.

4. Hydrotherapy is an ancient measure, universally. found, possessing cleansing, antiseptic, thermic and mechanical powers.

5. Its physiologic action on the human body is largely brought about through disturbing influences of temperature, and mechanical effects on peripheral sensory nerves.

(i. Brief applications followed by reaction do not particularly affect temperature.

\%. The circulation is increased on the surface by heat, and is accompanied by dilated blood-vessels, quickened heart action and lowering of arterial tension. Cold contracts the surface of blood-vessels, slows the heart's action, decreases the pulse-rate and raises arterial tension; it is followed by reaction with moderately dilated blood-vessels.

8. Respirations are increased in number, lessened in depth, and oxygen and carbon dioxid diminished by heat. Cold, on the contrary, increases the amplitude and deptl as well as the absorption of oxygen and the elimination of carbon dioxid.

9. On the nervous system, the direct action of water through its thermic and mechanical effects is conveyed to the center and there reflected in a thousandfold way, producing results both tonic and sedative that make it a true reconstructor.

10. Metabolism in all its phases is affected by hydrotherapy, less in degree in the case of heat than with cold. As a tissue up-builder, tonic, stimulant, eliminant and depletive, it is unequaled.

11. Muscular tissue is relaxed and enervated by heat: stimulated, revivified and toned $331 / 3$ per cent. by cold. 
12. The blond is changud, leukocytosis induced, opsonic index raised, purification promoted, hemoglobin increased, corpuscles enriched and the alkalinity made greater by these applications.

13. Many methods may be employed, but tonic (cold) hydrotherapy, followed by reaction, is the aim and object to be achieved. Thiese may be both general and local.

14. Tonic (cold) hydrotherapy when properly used restores and maintains neural health as well as general betterment of the bodily functions.

15. It increases drug absorption and distribution, and eniances their plyysiologic artion and therapentic possibilities.

16. It belongs to seientific medicine and should take its place alongside of the other valuable medical and surgical methods that form the physician's armamentarium.

115 West Chestuut Street.

\section{ABS'TRACT OF DISCUSSION}

1):3. G. Reiron Massiey, Pliladelphia: I do not like the term "futigue neurosis" for these conditions. The worl "fatigne" in this commection is unfortunate because it hits eaused the society belle to think that all she has to do is to go to bed in order to get rid of it. Now what are doctors to do? The rest-cure tlat was made famous some years ago lyy one of the most eminent members of the profession hat the serious disadvantage of overlooking the fact that what is wanted is this physiologic cleaning out and stimulating. The rest-cure on analysis in the hands of its best users will lie found like the sanatorium treatments, a profound, rigid, moral box in which the patient is placed to be emotionally and physically played on by the physician, the rest being one of the most incidental parts of the whole thing.

Dr. Cunnan Pore, Jouisville, Ky.: J differ with Dr. Massey, in that I think the term "fatigue" is much better than the term "neurastlienia." We are all of us prone, though, to quarrel with terms. If we can ouly understand what the terms mean, and if we will only interpret the condition and not the term and treat the patient and the condition and not the mane and the term, we shall frequently do better work.

\section{THE QUALITY OF DRUGS SOLD TO DISPENSING PHYSICIANS *}

\section{W. A. PUCKNER, PIIAR.I). \\ Ifrector of the Chemfeal Laboratory of the Americun Medicul Assoclution \\ CIIICAGO}

Last year in reporting the work of the Chemical Laboratory of the American Medical Association bearing on the quality of unofficial and little-used drugs I took the ground thiat drugs which were widely used and which were sold under competition were likely to be of good quality and that, on the other hand, little-used drugs were unreliable and likely to be of poor grade. While this contention, if correct, would indicate that standard drugs would be of good quality, no matter where purchased, it hos been said repeatedly and insistently in pharmaceutical circles" that the drugs sold by "phy-

* Read in the Section on Pharnacology and Therapeuties of the American Medleal Associstion, nt the Sixty-Fourth Annual Session, held ut Minneltpolls, June, 1013.

1. IReport of the Commitlee on Drue Reform Amoriean Pharmacentical Assoctation, sixtleth annual meeting, Denver, Aug. 19, mlte, Am. Druggist, September, 1912, p. 5Q. Report of the Comslxteth annial meet!ng, Denver, Aug. 19, 1012, Am. Drugglst, septeruber, 1012, p. 55 . sicians' supply houses" are uniformly of poor quality. In general those who made these charges gave no specific proof of their assertions, and since pharmacists suffer financially through the clispensing of medicines by physicians these charges did not appear particularly convineing. That the charge that physicians dispense poor drugs was dictated largely by the pharmaceutical opposition to such dispensing by physicians is perhaps best shown by the attitude taken by certain drug journals, which by inference, if not directly, take the stand that all physicians who dispense their own medicines are quacks, as may be illustrated by the following:

In the Chicago Retail Druggists Association's C. R. D. A. New's, I)ec. 28, 1912, was published an article entitled "The Quack Dispensing Plysician in Chicago," regarding whom it was said: “. . . they put up the cheapest pill or tablet they can buy from some obscure pill factory and which in most cases would do good service if loaded into shotgun shells for the sportsman in quest of game."

$\Lambda$ cartoon from the Retail Druggist was published in N. A. R. D. Notes, the official journal of the National $\Lambda$ ssociation of Retail Druggists, Oct. 24, 1912, p. 135, entitled "Time to Rescue the Woman from the Gorilla," in which is depieted a large gorilla, "the dispensing doetor-quack," rumning off with a woman, "innocent patient."

As a large number of physicians for some reason or other dispense their own medicines, it seemed desirable that an investigation of the drugs sent out by these houses be made in the Chemical Laboratory of the American Medieal Association and the findings published, so that physiciuns miglit learn something of tho gencral reliability and competence of this class of pharmaceutical concerns. This seemed the more important sinee, it having been shown that the quality of drugs depends on competition, a report on the nature of these drugs would bring about more real competition-that is, the giving of preference, if differences exist, to those firms which supply high-quality drugs at moderate cost.

As stated before, those who have made the general charges of unreliability against the "physicians' supply houses" did not offer specific information as to the drugs which had been found inferior or to the firms which had been proved unreliable. A list of "physicians' supply houses" deemed worthy of investigation was offered, however, and it is the products of these firms which it was undertaken to investigate. As the charges against the houses which make a specialty of supplying physicians included both dishonesty and incompetence, specimens were purchased which should show whether or not these firms sell adulterated drugs and also show their competence in so far as they sell products of their own manufacture. As it has been shown repeatedly2 that in the case of little-used drugs or unscientific complex mixtures few, if any, pharmaceutical manufacturers have cared much regarding the quality of such preparations, in this examination only staple drugs were selected. The drugs were purchased by an Illinois physician from the following "physicians' supply houses":

2. Unofhclal Preparatlons of Ilyclastis (Golden Senl), Rep. Chem. Iab. A. M. A., 1908, p. 28 , 'THE JuUnal, A. M. A. July 4. 1908 , p. $\overline{0} 2$. IExaminntion of 'l'nblets of Bismuth, Oplum and l'henol, Rep. Chem, Lab., A. M. A., 1008, p. 28, THe JoukNat. A. M. A., July 25, 1908 , p. 330. Zinc Permangmnate, Irep. Chem.

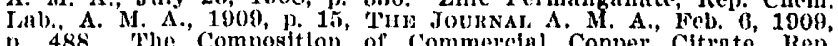
p. 488. The Composition of Commercla Copper Citrate, Rep. Chem. Lab. A. M. A., $1010, \mathrm{p}$. 27. The Composltion of Strychnln Arsenate, liep. Chem. Iab., A. M. A., 1910, p. 35, 'PHE Joulnal A. M. A., Sept. 24, 1910, p. 1128. Alomutc ligestive 'ablets, Rep. 1010 , p. 710 . 